\title{
Azerbaijan Republic: Joint Staff Assessment of the Poverty Reduction Strategy Paper Progress Report
}

The attached Joint Staff Assessment (JSA) of the Poverty Reduction Strategy Paper Progress Report for the Azerbaijan Republic, prepared by the staffs of both the World Bank and IMF, was submitted with the member country's Poverty Reduction Strategy Paper (PRSP) Progress Report to the Executive Boards of the two institutions. A JSA evaluates the strengths and weaknesses of a country's poverty reduction objectives and strategies, and considers whether the PRSP provides a sound basis for concessional assistance from the Bank and Fund, as well as for debt relief under the Enhanced Heavily Indebted Poor Countries (HIPC) Debt Initiative. The Boards then decide whether the poverty reduction strategy merits such support.

To assist the IMF in evaluating the publication policy, reader comments are invited and may be sent by e-mail to publicationpolicy@imf.org.

Copies of this report are available to the public from

International Monetary Fund • Publication Services

$70019^{\text {th }}$ Street, N.W. • Washington, D.C. 20431

Telephone: (202) 623-7430 • Telefax: (202) 623-7201

E-mail: publications@imf.org •Internet: http://www.imf.org

Price: $\$ 15.00$ a copy

\section{International Monetary Fund Washington, D.C.}





\author{
INTERNATIONAL MONETARY FUND \\ AND THE INTERNATIONAL DEVELOPMENT ASSOCIATION
}

AZERBAIJAN REPUBLIC

\title{
Poverty Reduction Strategy Paper Progress Report Joint Staff Assessment
}

Prepared by Staffs of the International Development Association and the International Monetary Fund

Approved by Shigeo Katsu and Gobind Nankani (IDA) And Lorenzo Pérez and Martin Fetherston (IMF)

August 12, 2004

\section{OVERVIEW}

1. The Government of Azerbaijan has prepared the first Annual Progress Report of its Poverty Reduction Strategy Paper, known as the State Program for Poverty Reduction and Economic Development (SPPRED). The SPPRED was approved on February 20, 2003 and presented to the Boards of the IMF and IDA on May 14 and May 27, 2003 respectively. This Progress Report presents the results of the implementation of the SPPRED. The Report is a well structured document presenting a review of measures taken to date to achieve the goals set in the SPPRED and identifying areas for further improvement. It addresses six key areas: (i) SPPRED and Millennium Development Goals (MDGs); (ii) economic growth and employment; (iii) social policy and human capital; (iv) regional policy; (v) institutional reform and capacity building; and, (vi) the participatory process. In addition, the Report updates the poverty profile, analyzes the main poverty indicators, and discusses ways to improve poverty monitoring.

\section{The Progress Report indicates that the Government has had a number of} accomplishments in the implementation of the SPPRED and stresses the need to further accelerate execution of the identified policies and programs to meet the desired goals. Accomplishments include (i) a new Household Budget Survey to update and improve the analysis of poverty; (ii) strengthened capacities of the SPPRED Secretariat through establishment of a Monitoring Unit; (iii) a new Budget Systems Law that integrates extra 
budgetary funds into the state budget; (iv) improved costing and prioritization of the SPPRED through the Medium Term Expenditure Framework (MTEF); (v) enhanced links between the SPPRED and the MDGs; (vi) a medium term strategy for enhancing targeting of social assistance; and (vii) established audit institutions and adopted a governance and management framework for the Oil Fund. The progress report placed continued emphasis on macroeconomic stability and economic growth as key instruments to generate employment and achieve poverty reduction objectives. The Report highlights the need to strengthen institutional capacities and the removal of administrative barriers to economic activity and to improve the efficiency and effectiveness of the public sector in general, and social policies in particular. It also identifies challenges in achieving the MDGs, particularly the lack of adequate data to set benchmarks and monitor progress, and notes the need to develop specific indicators as one of the Government's immediate tasks.

3. However, the Report does not incorporate some of the recommendations flagged in the JSA of the SPPRED and suffers from weaknesses in several areas. The Report is weak in the analysis of policies in key sectors, identification of problems in the implementation of the SPPRED, and in the discussion of alternatives to enable the main poverty reduction objectives to be met. Prioritization of projects and analysis of project costing needs to be further strengthened, together with detailed analysis of the budgetary allocations across key sectors. While the Report incorporates the MTEF in its discussion of SPPRED objectives, it does not elaborate on efforts made to carefully design the Long Term Oil Revenue Management Strategy which is critical in developing the long-run strategy for poverty reduction. There is limited discussion of the governance issues in the social sectors, which impede efficient implementation of policies to fulfill SPPRED objectives. Finally, the Report could have made some suggestions to improve engagement of key line ministries to the main goals of the SPPRED.

\section{The Participatory Process}

4. The Progress Report reflects an extensive process of consultation involving the Government, civil society, the private sector, and the donor community. This has resulted in the participatory process broadening and becoming an integral part of SPPRED implementation. The 15 Sector Working Groups setup for the SPPRED, composed of both government and civil society representatives, continue to be functional. Policy formulation as well as changing priorities have been discussed with, and communicated to, the general public through regional Town Hall meetings, seminars, workshops, and the mass media. This has helped increase the public's general interest in the SPPRED and MDGs, and increased feedback on improving the SPPRED agenda in terms of prioritizing and sequencing. Donor participation and coordination has also improved significantly and multiple donors are involved in various aspects of the poverty reduction programs of the Government. USAID, 
the EU and other donors are directly supporting the SPPRED secretariat and deriving their program according to the agenda. ${ }^{1}$

5. The consultation process has significantly increased public awareness and interest in debating key policy issues. There is a new openness to discussing and analyzing the economic reform agenda of the Government. Over the last year, the consultation process has improved the ability of communities to analyze the emerging problems and to propose ways for their solution. Public debate has been conducted through a broad range of activities, public information has been increased through radio and TV broadcasting, newspapers and website forums, and trainings in participatory methods, particularly by local communities and municipalities, have been conducted by NGOs.

6. In staffs' view the participation process needs to be institutionalized and become an integral part of policy formulation in Azerbaijan. The staffs believe that greater ownership would be fostered if the Government generated well-focused and realistic action plans directly from the participatory process. An enhanced role for Parliament, which has already demonstrated its commitment to the SPPRED implementation through the PRSP Support Group, would also be an important step in this process. The staffs welcome the efforts to improve the coordination of the assistance provided by the donor community and believe that this has been instrumental in engaging the donors in the implementation of the SPPRED.

\section{UPDATED POVERTY Diagnostic}

\section{The Progress Report presents an updated poverty diagnostic based on the} Household Budget Survey (HBS) for 2002. Poverty is estimated at 46.7 percent of the total population with an extreme poverty incidence of 8.8 percent. The Report highlights the changes to the HBS questionnaire in 2002 to achieve consistency with EUROSTAT. These changes, together with changes in the calculation of poverty aggregates and the poverty line, preclude the comparison of poverty estimates between 2001 and $2002^{2}$. In spite of this, the Report could have conducted a more rigorous comparison of the changes in poverty rates over the two years, for example, by calculating rates based on the same food-item derived

\footnotetext{
${ }^{1}$ Other examples of enhanced donor coordination include budgetary reform, in which the Bank and the Fund are working closely together with USAID and the US Treasury, as well as accounting reform, where we work as one team with EU TACIS.

2 The main differences include (i) changes in the definition of consumption expenditure in the HBS questionnaire; (ii) differences in the poverty lines with 2002 figures defining a minimum consumption basket for food and non-food products, and 2001 figures incorporating only food items; and (iii) changes to the weights and prices of items in aggregating the consumption basket.
} 
poverty line. Furthermore, although substantial changes are not expected to be introduced to the survey methodology, the Government needs to ensure that future revisions or modifications of this methodology do not adversely affect data consistency and comparability.

\section{Despite the change in methodology, the 2002 data do not show a significantly} different poverty profile for Azerbaijan. The incidence of poverty remains slightly higher among urban than rural households- 47.8 percent compared to 45.4 percent respectivelyand is associated with falling employment opportunities and earnings in the formal economy. Although Baku (with a poverty rate of 40 percent) has the largest absolute number of urban poor, poverty incidence is highest in provincial towns. Rural areas and small towns are more deficient in terms of access to basic services, inadequate infrastructure, and unreliable supply of energy and gas, factors that contribute to intense rural-urban migration and discourage investment in the regions outside Baku. With respect to individual and household characteristics, children under 15, and households with 3 or more children, experience the highest poverty risk.

9. Setting up a system to monitor living standards has been a major achievement to date, but the monitoring of those standards for refugees and internally displaced persons (IDPs) has serious shortcomings. ${ }^{3}$ The SPPRED Secretariat uses a wide range of indicators on living standards for education, health, employment, environment, and gender to monitor poverty and assess the overall progress in these areas. However, as the Report notes, there are sizeable deficiencies in monitoring the living standards of IDPs and refugees who are most vulnerable to poverty. No progress has been made in the introduction of a unified annual survey as had been envisaged by SPPRED. Monitoring living standards of IDPs and refugees has therefore relied on various one-time surveys designed to meet different needs and the HBS, resulting in a lack of coherent, periodic, and systematically comparable collected data.

10. The Report assesses the impact of education and health services on poverty and provides detailed assessments of measures to improve data quality. The Report finds that households with heads educated to higher levels are less likely to live in poverty. It also notes that since current personal expenditures on education are low the possible decline in the country's human capital could have serious implications for poverty. The staffs commend the authorities for the Report's detailed analysis of data issues in the assessment of health policies through presentation of unofficial survey data which demonstrate that official data underestimate the real health situation. It is welcome that the SPPRED aims at improving the registration of infant and child deaths in order to produce reliable data. This, together with the

\footnotetext{
${ }^{3}$ IDPs of the Nagorno Karabakh conflict, who lack assets and depend heavily on State transfers, are particularly vulnerable. The conflict resulted in nearly 209,000 refuges and 576,000 IDPs according to official registration, in total almost 10 percent of the population.
} 
improved health information system and the international statistical classification, will contribute to the elimination of discrepancies in certain key health indicators. In staffs' view the SPPRED should continue to focus on improving quality and accessibility of education and health services and developing a reliable database to assess progress.

\section{The staffs recommend future Progress Reports include a broader analysis of} labor market issues and explore in more detail the link between poverty and the ongoing reforms in key sectors. The staffs commend the Government for the analysis of employment trends through introduction of the Labor Force Survey (LFS). The LFS estimates the overall unemployment rate (10.7 percent) and labor force participation rate (62.9 percent), which is high by international standards; employment to population rate (56.2 percent); and an inactivity rate for women, which is higher than for men in the 25-59 age group. It is important the LFS be conducted on a regular basis since the administrative data do not cover the informal sector. In addition, the staffs suggest that poverty analysis be integrated with the LFS to better enable future analysis of the working poor. In staffs' view, the assessment of poverty reduction in the context of the SPPRED goals would improve greatly if the future reports explore in more detail the link between poverty and the on-going sectoral reforms. In this respect, the staffs recommend social incidence analysis of public expenditure allocation, and the integration of qualitative data in poverty diagnosis to better assess the effect of SPPRED projects. The staffs commend the Government for including a matrix showing the MDGs (Appendix 1 of the Progress Report) and the status of actions in the case of each target.

\section{IMPLEMENTATION AND UPDATING OF THE STRATEGY}

\section{The Progress Report reviews progress made in implementation of SPPRED}

policy measures but is relatively weak in critically assessing achievements and in providing specific measures to improve the effectiveness of public policies. A large part of the Report focuses on what has been achieved without providing much data on specific indicators. The

Report stresses the importance of reporting on all standard MDGs annually. Substantial work, however, is needed to better prioritize the strategic focus of the SPPRED and to better estimate the cost of public action in each area.

\section{A. Macroeconomic Policies and Public Expenditure Management}

13. In staffs' view the macroeconomic framework continues to be broadly consistent with the Government's poverty reduction objectives and the stability of inflation and exchange rates. The framework targets real GDP growth of around 11 percent per annum over the period 2003-05 which is consistent with the SPPRED reform objectives and the average growth in the non-oil sector over the period 2000-2002. The oil-sector is forecast to receive a major boost in 2005 with a growth rate of around 40 percent. While such a rapid expansion of the oil export sector - which now comprises one-third of the economy-runs 
the risk of impeding growth in the non-oil sector, the foreseeable rapid profit repatriation and the planned build up of the oil fund will help limit the Dutch disease risks. However, continued fiscal prudence will remain necessary, and an expansion of tools with which the Azerbaijan National Bank can sterilize its interventions in the exchange market is urgently needed. Real growth in the non-oil sector is projected to average 9.7 percent between 20032005. Although the scenario presented is realistic, the Report could usefully have presented alternative scenarios and policy considerations to deal with exogenous risks such as volatility of world oil prices. In addition, a clearer assessment of material changes to the macroeconomic framework relative to the SPPRED would have been welcome, particularly as regards non-oil growth. Finally, the period of reference should have been 2004-2006 as the Report is focusing on developments in 2003 and the macroeconomic framework extends only to 2005. This limits the impact of the annual progress report in providing guidance for medium-term expenditure prioritization and, indeed, project selection beyond 2005.

\section{The staffs believe that the continuation of prudent fiscal policies is essential to} Azerbaijan's economic stability and balanced growth. Azerbaijan has a relatively solid track record of macroeconomic stability, notwithstanding the high oil prices and the associated sizeable capital inflows. There has been a steady improvement in Azerbaijan's Country Policy and Institutional Assessment (CPIA) rating since 2000 and its ranking among IDA countries has improved from fourth quintile in 2000 to second quintile in 2003 . The Government is gradually aligning budgetary expenditures with SPPRED priorities as noted by the Report. Expenditures on education and health are still low as a ratio of GDP relative to other countries, but the 2004 budget did allow for a significant increase in the level of allocations to these sectors. ${ }^{4}$ This apparent change in the trend is significant given the importance of social expenditures for poverty alleviation. The efficiency of these expenditures should be monitored carefully given institutional capacity and governance issues in the social sectors.

\section{Maintaining prudent fiscal policy in turn depends on the use of oil revenues.}

With the establishment of the State Oil Fund prudent arrangements have been made to manage oil revenues prior to their expenditure. A Long Term Oil Revenue Management Strategy, to guide the expenditure of these funds, has been drafted. The strategy aims to ensure that the substantial, but relatively short-lived, non-renewable oil and gas revenue windfall benefits both current and future generations by setting fiscal rules which target a constant real non-oil deficit with a limit on the year-to-year fluctuation in the non-oil deficit as a percentage of non-oil GDP. Formal adoption of the Strategy is an important next step. In

\footnotetext{
${ }^{4}$ Education and health expenditures grew by less than GDP on average during 1999-2003. In 2004, GDP is expected to increase by 16 percent in nominal terms, and total government spending (excluding BTC investments) by 25 percent. The Budget Law has allocated increases in expenditures of 27 percent for education and 32 percent for health in 2004 (in nominal terms, with an expected CPI inflation rate of 5 percent).
} 
addition, the implications of this strategy for budgetary allocations need to be discussed explicitly in future Progress Reports.

16. Progress in public expenditure management has been significant, but the growth in consolidated government expenditure needs to be better targeted, particularly in light of the pressing needs to meet the MDGs. The MTEF targets an increase in the ratio of government consolidated expenditure to non-oil GDP from 27.4 percent in 2001 to 33.4 percent in 2005. However, the staffs have some reservations regarding the composition of these expenditures which they believe should be targeted more toward poverty reduction and spending on basic services. First, although the government still needs to undertake much needed civil service reforms, significant and widespread wage (and pension) increases were introduced in 2003 and 2004, and more are planned for 2005. Second, the impact of budgetary spending in the priority sectors of health and, to some extent, education is adversely affected by serious governance problems at all levels, which the Government is not acting fast to address. This has prevented multilateral and bilateral assistance to the health sector in particular, and if continued, will adversely impact the Government's ability to meet the MDG goals. On the revenue side, the staffs believe a stronger effort should be made to broaden the non-oil tax base and lower tax rates, and continue structural changes to increase non-oil revenue performance. This is especially the case for taxes on labor, which are subject to very high social security contribution rates.

17. The Progress Report recognizes the importance of decentralization in the successful implementation of the poverty reduction strategy. Steps have been taken to improve local budget revenues and build capacity for local budget preparation. There is a need to focus on the creation of a transparent budgetary transfer mechanism and on the transfer of state properties to municipalities. The Report does not make clear why only onefifth of the budgeted transfers have been made available to the municipalities in 2003 . The need to further define the decentralization strategy and, in particular, the role of the municipalities remains an important priority for the Government. In particular, the creation of a governmental body responsible for municipal affairs is a priority in order to promote regional development objectives and engage in capacity building within municipalities.

18. The Progress Report lists the many actions taken by the Government, and planned for the future, to improve transparency and operational efficiency in the public and private sectors. A new Law on Budget System was adopted in July 2002 and amended in May 2003. The 2004 budget preparation was the first attempt with this Law. The Report does a good job of detailing the measures undertaken in tax and customs administration to improve transparency and governance, but it is silent on public procurement issues, the Chamber of Accounts, and the need to markedly improve the latter's effectiveness as an independent control agency. In order to strengthen the fiduciary framework, the Government is adopting a new Accounting Law that mandates the use of pure International Financial Reporting Standards (IFRS) by public interest companies, including large government enterprises, and the use of National Accounting Standards (NAS) by all other entities. The law also provides the basis for adoption of International Public Sector Accounts Standards (IPSAS) for government accounting. The accounting and auditing framework for 2004-2006 
envisages revisions of laws and related regulations to harmonize with the Civil Code and the Joint-Stock Company Law, and establishment of a new Audit Law according to International Standards of Auditing (ISA).

\section{B. Sector Policies}

19. The Progress Report puts special emphasis on the accessibility of education and basic health care services and the implemented policies to achieve the SPPRED goals. However, the Report is silent on key factors affecting the quality of education, such as class size, and the required policy steps to improve delivery of education services. With regard to health, advances have been made with the development of a basic health package, establishment of community drug funds, and community health councils on a pilot basis. Capacity has been built, and awareness raised through training and seminars, to increase birth safety and deal with AIDS, Malaria, and TB, while monitoring has been strengthened in order to reduce incidence. However, the Report does not adequately address the reasons for health care expenditures persistently being less than 1 percent of GDP. It understates the serious governance issues within all levels of the health sector including the chronic problem of informal payments and the pseudo privatization of health services. Without improvements in governance, envisioned increases in health care expenditures are unlikely to be used efficiently.

20. The Government program on social protection will focus on a range of actions aimed at increasing efficiency, effectiveness and sustainability and supported by the IDA Pension and Social Assistance Project. In the area of social insurance, the program includes linking benefits more closely to contributions; modernizing and strengthening financial management of the State Social Protection Fund (SPF); and moving all social insurance benefits administration from enterprises to the SPF. The Government will draft a new legislation on pensions, which will introduce parametric changes in the pension system and closer links between contributions and benefits. With regards to social assistance, the Government's program includes: (i) targeting of social assistance benefits based on eligibility assessment taking into account the economic and social situation of the applicants; (ii) consolidating various benefits into a single targeted family poverty benefit in cash as of 2006 and a significant increase of resources allocated to its financing; (iii) modernizing the capacity of Ministry of Labor and Social Protection (MoLSP) to administer social assistance benefits using computerized MIS. A draft framework law on Targeted Social Assistance has been submitted to the Cabinet of Ministers. The Staffs support the Government's strategy of linking these programs with the ongoing utility sector reforms in order to mitigate any adverse impact on the poor.

21. The Report recognizes the Government's efforts to reduce energy subsidies, intensify reforms in the energy sector, and provide reliable energy sources outside the capital city. The 2003 budget incorporated energy-related subsidies provided by the State Oil Company of the Azerbaijan Republic (SOCAR) to Azerenergy, Azerigas, and Azerchemia. In 
order to control the level of these subsidies, the Government approved the 2004 revenue and expenditure plans of these companies. The staffs welcome these developments, but believe the Report should highlight the difficulty the Government is facing in controlling and reducing energy-related subsidies, and in lowering the large quasi-fiscal subsidies implicit in oil product prices which are approximately 62 percent of world market rates. The overall situation with respect to supply of commercial energy outside Baku continues to be unsatisfactory, as power is supplied a limited number of hours per day. Furthermore, the increase in electricity and natural gas consumption in 2003 was matched by an increase in supply costs, causing the subsidy to the energy sector from the state budget to expand significantly. The Government intends to develop a medium-term tariff policy (in parallel with developing improved social protection) and to establish an independent utility regulatory agency. A Presidential Decree issued in January 2003 identified a number of restructuring initiatives aimed at SOCAR, including the separation of non-core activities in advance of their privatization, but their implementation has been limited and further work is needed. Recommendations for financial restructuring of SOCAR have been prepared and additional technical assistance is under preparation to review the commercial structure of SOCAR and implement a plan for the commercialization of the company.

\section{The Progress Report recognizes the importance of the agriculture sector in the} development of the regions. The Government has taken several measures in the agricultural sector. It has prepared a rural development strategy, taken steps to enhance the access of farmers to finance, developed the land market, and improved access to water. The staffs believe that the SPPRED should further encourage the enabling environment for the development of small- and medium-sized businesses in rural areas. This requires a reduction in transaction costs for businesses and development of marketing infrastructure. These entail improving the reliability of infrastructure, reducing corruption, and increasing economies of scale by facilitating the formation of rural business associations, for example for milk producers and processors. Other priority areas for improving the rural business environment include enforcing consistent and transparent standards for private sector activities.

\section{The Progress Report relates improving living standards to the improvements of infrastructure facilities in both rural and urban areas. Progress has been made in} construction and rehabilitation of highways, rural roads, railroads, and the airport in the Nakhchivan enclave. However, additional progress can be made in improving infrastructure by providing municipal governments with adequate resources and capacity to manage their infrastructure assets. Communities can play a significant role in addressing the issues related to improvement of rural infrastructure. The staffs support the Government's intention to encourage community development and recommend preparation of a strategy for this purpose. It is important that the Government puts into effect the provision of timely registration of community-based organizations to enable the latter to fully participate in the community development processes.

24. The Progress Report highlights a number of measures to strengthen the banking system and to broaden its out-reach, but recognizes that more remains to be done. Measures taken include expansion of the banking network in the regions, creation of a 
functional micro-finance market, expansion of credit unions, and improved access to finance in rural areas. The registration process and regulatory framework for non-bank credit institutions (microfinance institutions and credit cooperatives) has been streamlined, which has increased the number of institutions and credit volume. Yet, the total volume of credit to rural areas and to the disadvantaged remains small. What is needed to reduce credit risk are parallel actions that would facilitate appraisal and management of credit risk for non-bank financial institutions and create better business and market environment for the private sector in the regions. The Report fails to highlight the substantial delays in the privatization of IBA and BUS Bank, and their much needed subsequent de-monopolization. In fact, over 2003 and 2004, IBA has consistently attempted to consolidate its monopoly power, sometimes with the assistance of the Government, as seen with the Social Protection Fund tender. The staffs recommend these issues be raised in future progress reports, as they must be addressed to foster competition and efficiency in the banking sector and to develop a sound financial sector, which is essential for the future development of the economy.

\section{In staffs' view, measures to strengthen the banking system and its legislation would contribute to the stability of the financial markets. While the recently enacted} Banking Law is consistent with Basel Core principles, the associated implementing decree raises serious problems for independent regulation of the banking sector by effectively transferring control of supervision to the Presidential Office. Furthermore, the decree calls for a Banking Sector Codex, details of which are unclear but which has effectively stalled progress on the draft National Bank Law. The latter aimed to improve the quality of banking supervision and regulation, as well as the disclosure of information, which would affect transparency in the banking sector and market operations. In spite of these impediments, there has been some progress in improving the banking infrastructure. The creation of a credit register is expected to improve banks' credit risk management capacity and facilitate access to credit. There have been important advances in improving bank governance and in introducing international accounting and reporting standards in the banking sector. The national payment system has gone through further improvement and the NBA has started developing a comprehensive system to introduce electronic payment means. The real difference and positive impact that these actions will have on the banking system and access to finance will, however, take some time to materialize, and could be overwhelmed by the supervision problems noted above. Expanding access to the national payments system and financial services to rural areas would help integrate these areas into the national economic sphere.

\section{The Progress Report attributes importance to the actions taken to create} favorable conditions for income-generating opportunities. It elaborates on the adoption of new laws facilitating the registration of legal entities and combating corruption, and emphasizes other positive developments including the simplification of the licensing system, implementation of the program on the development of Small and Medium Enterprises, promotion of investments through creation of a foundation for investment promotion, development of a public investment program, and reductions in the tax burden and simplification of the tax system. In addition, WTO accession has been facilitated through various technical assistance programs. The staffs recommend that the Government focus even 
more attention on eliminating impediments to private sector development and foreign direct investment, including unreliable utility and infrastructure services, especially in the regions outside Baku, as well as administrative barriers to business start-up, and site acquisition and development.

27. The Progress Report clearly defines the challenges of maintaining environmental sustainability as the economy expands. There is a need for greater monitoring and control of pollution levels. SPPRED is addressing the shortage in household drinking water supply and inadequate water quality (especially in rural areas) through rehabilitation of infrastructure in a number of regions, with the help of the donor community. A national forest rehabilitation plan, adopted in 2002, has been implemented to meet the SPPRED objective of creating and expanding forestry areas. The staffs concur that institutional capacity for monitoring environmental problems and developing an effective regulatory framework should be at the core of SPPRED activities.

28. The Progress Report recognizes that gender issues have not received sufficient attention. The staffs recommend that this be addressed in a more systematic way in the next progress report, with a clear mechanism in place that would enable the utilization of various data sources for an effective assessment of gender as it relates to poverty. In staffs' view the SPPRED could take stock of all activities supported so far by both the Government and donor community and conduct a country gender assessment.

\section{Monitoring AND Evaluation}

29. The staffs welcome the establishment of the Poverty Monitoring Unit at the SPPRED Secretariat and efforts to build capacity for poverty analysis. The SPPRED Secretariat continues to monitor changes in poverty levels and, where possible, analyzes the effect of policies on poverty results. Capacities also need to be strengthened in key line ministries to undertake policy monitoring and evaluation. The next progress report will need to be more explicit on monitoring of outputs and outcomes. The staffs welcome the Government's intention to gradually expand the core set of indicators, especially for measuring the targeting of social services. Reporting annually on all the standard MDGs is critical.

\section{The staffs encourage establishing annual surveys such as the Labor Force} Survey, the survey of IDPs, and others that would assist Azerbaijan in setting up a credible database for monitoring poverty and living standards. It is important to continue to make data available for independent researchers as part of the participatory process. Education and specially health sector data need to be dramatically improved. The staffs welcome the Government's engagement in the Poverty and Social Impact Analysis (PSIA) on energy tariff reform and on worker displacement due to the enterprise restructuring and privatization. 


\section{RISKS TO THE STRATEGY}

31. In the staffs' view, the Strategy is subject to several institutional and political risks that are not evaluated in the Progress Report. The leading one is the implementation risk resulting from weaknesses in coordination among line ministries and multiple agencies in charge of the implementation of policies and programs identified by SPPRED. In addition, capacity constraints and governance problems in line ministries could pose risks in full implementation of the SPPRED programs. There is also a risk that power struggles as a result of the recent political transition could lead to major shifts in policies. In the staffs' view, future Progress Reports should include an assessment of the exogenous risks and detail plans to mitigate them. The Government also needs to develop contingency plans and alternative scenarios and policy considerations to deal with these risks.

\section{CONCLUSIONS}

32. The Government of Azerbaijan has made significant progress in implementing the SPPRED within a short period of time, notwithstanding the political challenges in 2003. Although there are weaknesses due to insufficient implementation capacity, in staffs' view the Progress Report is a credible and inclusive effort on the part of the Government and provides a basis for more harmonized and effective donor support.

33. In staffs' view there are some shortcomings that need to be addressed during implementation of SPPRED and in subsequent progress reports. First, the analysis of poverty needs to be strengthened by expanding the information base to include labor market surveys and social impact assessment. Health statistics, in particular, need to be improved urgently. Second, policies should be better prioritized to identify pro-poor spending programs. Third, the link between policies and budgetary allocations needs to become stronger through the MTEF process. This requires detailed analysis of budgetary allocations across key sectors and their poverty implications, as well as a more critical review of government policies in each area to identify the need for future support. Fourth, capacity constraints need to be further analyzed and clearly identified, including the need for possible support from the donor community. Fifth, more accurate costing of programs is needed. Finally, more attention needs to be paid to the analysis of gender issues.

34. The staffs of the IDA and the IMF consider that Azerbaijan's poverty reduction strategy continues to provide a credible framework for Bank and Fund concessional

assistance. The staffs recommend that the respective Executive Directors of the World Bank and the IMF reach the same conclusion. 